\title{
Lapatinib in the Treatment of Hormone Receptor- Positive/ErbB2-Positive Breast Cancer
}

\author{
Ingo Bauerfeind ${ }^{\mathrm{a}}$ Dirk Elling ${ }^{\mathrm{b}}$ Volker Heinemann ${ }^{\mathrm{c}}$ \\ ${ }^{a}$ Brustzentrum Klinikum Landshut, \\ ${ }^{\mathrm{b}}$ Frauenklinik, Sana Klinikum Lichtenberg, Berlin, \\ ${ }^{\mathrm{c}}$ Medizinische Klinik und Poliklinik, Klinikum der Universität München, Campus Großhadern, München, Germany
}

\section{Key Words}

ErbB2-positive breast cancer - Hormone receptors .

ErbB2/ER pathway crosstalk - Endocrine resistance . EGF30008 trial

\section{Summary}

In women with estrogen receptor(ER)- and ErbB2 (HER2)positive breast cancer, a vicious cycle is established between ER mechanisms of action and the growth factor receptor network, leading to enhanced cell proliferation and endocrine resistance. As such, co-targeting ErbB1 and ErbB2 with lapatinib in combination with hormonal therapy is an attractive approach to enhance the efficacy of either tamoxifen or estrogen deprivation. As demonstrated in the EGF30008 trial, a combined targeted strategy with letrozole and lapatinib significantly increased progression-free survival and clinical benefit rates in patients with metastatic breast cancer that co-expresses $\mathrm{ER}$ and ErbB2. Therefore, women who are not in an acutely life-threatening situation should be considered for upfront treatment with hormonal therapy (e.g. aromatase inhibitors) in combination with an anti-ErbB2 therapy.

\section{Introduction}

Co-expression of ErbB2 (HER2) and hormone receptors (HR) is a rather uncommon histopathological dualism: approximately half of ErbB2-positive breast cancers also express HR [1], accounting therefore for $10-15 \%$ of all breast cancer patients. It is generally accepted that women with HR-posi-

\section{Schlüsselwörter \\ ErbB2-positives Mammakarzinom - Hormonrezeptoren . ErbB2/ER-Pathway-Crosstalk · Endokrine Resistenz . EGF30008-Studie}

\section{Zusammenfassung}

Bei Frauen mit Östrogenrezeptor- und ErbB2 (HER2)positivem Mammakarzinom wird ein Circulus vitiosus zwischen den östrogenrezeptorvermittelten Wirkungen und dem Wachstumsfaktor-Netzwerk in Gang gesetzt, der in einer gesteigerten Zellproliferation und endokriner Resistenz resultiert. Daher ist eine gleichzeitig gegen ErbB1 und ErbB2 gerichtete Therapie mit Lapatinib ein attraktiver Ansatz, um die Wirksamkeit einer antihormonellen Therapie zu steigern. Wie die Daten der EGF30008Studie zeigten, lassen sich mit der kombinierten Gabe von Letrozol und Lapatinib bei Patientinnen mit metastasiertem Mammakarzinom und Östrogenrezeptor/ErbB2Coexpression das progressionsfreie Überleben sowie der klinische Nutzen signifikant steigern. Daher sollte diese Kombination für Frauen, die sich nicht in einer akut lebensbedrohlichen Situation befinden, als Therapie der Wahl berücksichtigt werden.

\begin{tabular}{ll}
\hline KARGER & $\oplus$ 2010 S. Karger GmbH, Freiburg \\
Fax +497614520714 & Accessible online at: \\
Information@Karger.de & www.karger.com/brc \\
www.karger.com &
\end{tabular}




\section{ErbB2/ER Pathway Crosstalk and Endocrine Resistance}

Cumulative data from studies of estrogen receptor (ER) biology have identified a significant bidirectional crosstalk between the ER and growth factor-signaling networks, especially the ErbB2 signaling pathway. Estrogen has 2 known functional activities in breast cancer cells: in the classic genomic pathway, the hormone activates nuclear ERs, which leads to receptor phosphorylation, dimerization, and recruitment of co-activator proteins to the estrogen-bound receptor complex [1,4]. In addition, there is also an activation of ERs located outside the nucleus in the cytoplasm and non-nuclear subcellular fractions. This so-called rapid non-genomic activity leads to phosphorylation, and as a result, activation of surface tyrosine kinase receptors such as the insulin-like growth factor I receptor (IGF-IR) as well as the ErbB2 receptor. This seems to be the site where the crosstalk between ER and growth factor receptors occurs. The molecular crosstalk between those two receptor systems is continuous and bidirectional, and the two systems are able to activate each other $[1,4]$.

Estrogen-deprivation therapies such as aromatase inhibitors (AIs) abolish genomic and non-genomic activities of ER and, therefore, could terminate the crosstalk generated in the presence of estrogen or tamoxifen in ErbB2-positive disease $[1,5,6]$. Data from preclinical models, however, suggest that resistance to estrogen-deprivation therapies in ErbB2-overexpressing breast tumors might occur through at least 2 mechanisms: adaptation to an estrogen hypersensitive phenotype and/or by ligand-independent recruitment of co-activator complexes to estrogen-responsive promoters $[1,7,8]$.

Given the crosstalk activation, a treatment strategy of upfront dual targeting of both receptors with concurrent endocrine and anti-ErbB2 therapy appeared to be a logical approach to overcome or prevent endocrine resistance in patients with HR/ErbB2-positive tumors. Dual inhibitors of both ErbB1 and ErbB2 like lapatinib might be particularly suitable.

\section{Preclinical Data of Co-Targeting ErbB1 and ErbB2 with Lapatinib}

As shown in several preclinical studies, there is strong evidence that lapatinib may be effective in restoring tamoxifen sensitivity in HR-positive, tamoxifen-resistant breast cancer models. Chu et al. [9] demonstrated that lapatinib in combination with tamoxifen effectively inhibited the growth of tamoxifen-resistant, ErbB2-overexpressing MCF-7 mammary tumor xenografts. Leary et al. [10] showed greater antiproliferative effects for the combination of lapatinib with estrogen deprivation than either strategy alone in long-term estrogendeprived and tamoxifen-resistant cells derived from parental hormone-sensitive MCF7 cells as well as in BT474 cells, a cell line with ErbB2 amplification and known sensitivity to lapat-

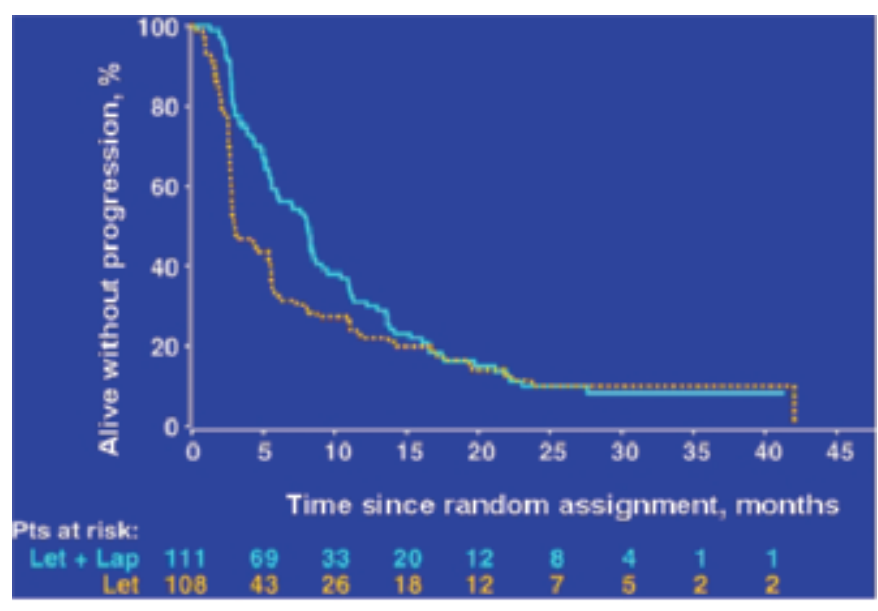

Fig. 1. Phase III EGF30008 trial: Kaplan-Meier estimates of progressionfree survival, adapted from [11].

inib. Furthermore, the addition of lapatinib significantly enhanced the sensitivity to tamoxifen.

\section{Clinical Evidence}

Based on this preclinical evidence, the question of combined therapy has been addressed by the randomized, double-blind, placebo-controlled, multicenter phase III EGF30008 trial evaluating the effect of adding lapatinib to the AI letrozole as first-line treatment [11]. A total of 1,286 patients with ERpositive metastatic disease were randomly assigned to receive daily letrozole (2.5 mg orally) plus lapatinib (1,500 mg orally; $n=642)$ or letrozole plus placebo $(n=644)$; of these, $17 \%$ of patients in each arm had tumors centrally confirmed in a commercial laboratory as ErbB2-positive $(n=111$ and $n=108$, respectively). Baseline patient and disease characteristics were well balanced between treatment arms for both the ErbB2-positive $(n=219)$ and intention-to-treat HR-positive populations. As seen after a median follow-up time of 1.8 years, the addition of lapatinib to letrozole significantly increased the median progression-free survival (PFS) for HR/ ErbB2-positive women $(\mathrm{n}=219)$ from 3.0 months (letrozoleplacebo) to 8.2 months, representing a statistically significant $29 \%$ reduction in the risk of disease progression (hazard ratio $(\mathrm{HR})=0.71 ; 95 \%$ confidence interval $(\mathrm{CI}) 0.53-0.96 ; \mathrm{p}=$ 0.019) (fig. 1). Consistent with these findings, the overall response rate (ORR) in the ErbB2-positive population was significantly improved from 15 to $28 \%$ for patients treated with letrozole-lapatinib (odds ratio $(\mathrm{OR})=0.4$; $95 \%$ CI $0.2-$ $0.9 ; \mathrm{p}=0.021$ ). Including patients with stable disease for $\geq 6$ months, the clinical benefit rate (CBR) was likewise significantly improved ( 29 to $48 \%$; OR $=0.4$; $95 \%$ CI $0.2-0.8$; $\mathrm{p}=0.003$ ). With less than $50 \%$ of overall survival (OS) events yet recorded, the median OS in the ErbB2-positive population was 32.3 months in the letrozole-placebo arm compared 


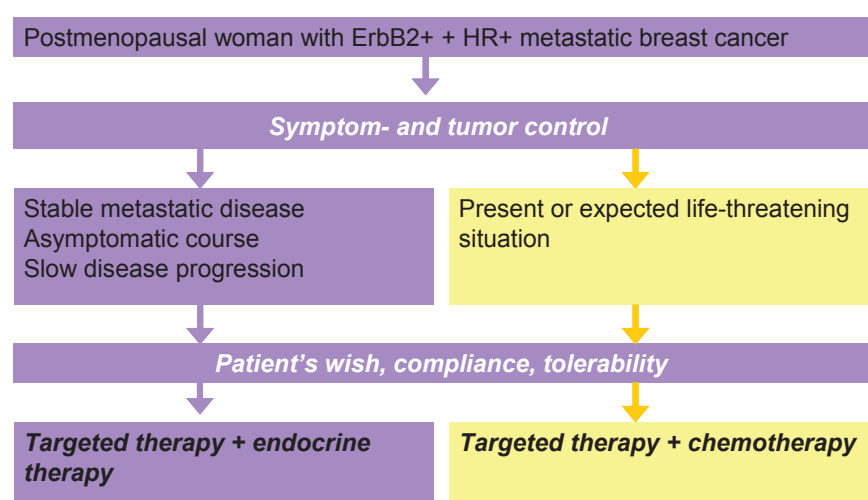

Fig. 2. Proposed therapeutic algorithm for the first-line therapy of women with HR/ErbB2-positive postmenopausal metastatic breast cancer.

with 33.3 months in the combination arm ( $\mathrm{HR}=0.74 ; 95 \% \mathrm{CI}$ $0.5-1.1 ; p=0.113$ ). Grade 3 or 4 adverse events were more common in the lapatinib-letrozole arm versus the letrozoleplacebo group (diarrhea 10 vs. $1 \%$; rash 1 vs. $0 \%$ ), but they were manageable. As the authors concluded, the EGF30008 trial demonstrated that a combined targeted strategy with letrozole and lapatinib significantly enhances PFS and CBR in patients with metastatic breast cancer that co-expresses HR and ErbB2.

\section{Anti-ErbB2 Therapy Combined with Endocrine Therapy or Chemotherapy?}

The combination of trastuzumab and chemotherapy offers a significant survival advantage when compared with chemo- therapy alone for patients with ErbB2-positive breast cancer, regardless of HR status $[12,13]$. On the other hand, patients have to tolerate the toxicities from the chemotherapy combination $[12,13]$.

Analogue to the therapeutic algorithm for ErbB2-negative patients in whom endocrine-based treatment or chemotherapy is depending on the number and site of the metastases, tumor growth dynamic, and life-threatening issues, the following therapeutic algorithm seems to be feasible when choosing a first-line therapy for women with metastatic HR-positive tumors overexpressing ErbB2 (fig. 2): combining chemotherapy with targeted therapy should be the first-line treatment option considered in patients with acute life-threatening disease. Patients who are not in an acute life-threatening situation should be considered for upfront treatment with hormonal therapy (e.g. AIs) in combination with an anti-ErbB2 therapy. As demonstrated in the EGF30008 trial (lapatinib + letrozole) [11] as well as in the TAnDEM trial (trastuzumab + anastrozole) [14], this is an appropriate approach to control patients for a significant period of time before chemotherapy (in combination with a targeted therapy) is required. Trastuzumab in combination with an AI is approved for this indication. The approval for lapatinib in combination with an $\mathrm{AI}$ is expected in 2010 .

\section{Disclosure Statement}

The authors were speakers and contributors to the meeting 'ErbB2 (HER2)-positives Mammakarzinom; 2. Münchner Brustkrebs-Symposium Update 2009', 23/24 October 2009 in Munich, sponsored by GlaxoSmithKline.

\section{References}

1 Prat A, Baselga J: The role of hormonal therapy in the management of hormonal-receptor-positive breast cancer with co-expression of HER2. Nat Clin Pract Oncol 2008;5:531-542.

2 Carlson RW, Allred DC, Anderson BO, Burstein $\mathrm{HJ}$, et al.: Breast cancer. Clinical practice guidelines in oncology. J Natl Compr Canc Netw 2009;7: 122-192.

3 Kreienberg R , Kopp I, Albert U, et al.: Interdisziplinäre S3-Leitlinie für die Diagnostik, Therapie und Nachsorge des Mammakarzinoms. Deutsche Krebsgesellschaft e.V. (DKG) und Deutsche Gesellschaft für Gynäkologie und Geburtshilfe (DGGG) 1. Aktualisierung 2008.

4 Arpino G, Weichmann L, Osborne CK, et al: Crosstalk between the estrogen receptor and the HER tyrosine kinase receptor family. Endocr Rev 2008; 29:217-233.

$\checkmark 5$ Ellis MJ, Coop A, et al.: Letrozole is more effective neoadjuvant endocrine therapy than tamoxifen for ErbB-1- and/or ErbB-2-positive, estrogen receptor-positive primary breast cancer: evidence from a phase III randomized trial. J Clin Oncol 2001;19:3808-3816.
6 Johnston S, Dowsett M: Aromatase inhibitors for breast cancer: lessons from the laboratory. Nat Rev Cancer 2003;3:821-831.

7 Osborne CK, Schiff R: Estrogen-receptor biology: continuing progress and therapeutic implications. J Clin Oncol 2005;23:1616-1622.

8 Massarweh S, Osbonre K, Joang S, et al.: Mechanisms of tumor regression and resistance to estrogen deprivation and fulvestrant in a model of estrogen receptor-positive, HER-2/neu-positive breast cancer. Cancer Res 2006;66:8266-8273.

9 Chu I, Blackwell K, Chen S, Slingerland J: The dual ErbB1/ErbB2 inhibitor, lapatinib (GW572016), cooperates with tamoxifen to inhibit both cell proliferation- and estrogen-dependent gene expression in antiestrogen-resistant breast cancer. Cancer Res 2005:65:18-25.

10 Leary AF, Martin LA, Lykkesfeldt AE, Dowsett M, Johnston SRD: Enhancing endocrine responsiveness using the dual EGFR/HER2 tyrosine kinase inhibitor lapatinib in cell models of endocrine resistance. Breast Cancer Res Treat 2006; 100(suppl): S29, abstr 303.
1 Johnston S, Pippen J Jr, Pivot X, et al.: Lapatinib combined with letrozole versus letrozole and placebo as first-line therapy for postmenopausal hormone receptor-positive metastatic breast cancer. J Clin Oncol 2009:27:5538-5546.

12 Slamon DJ, Leyland-Jones B, Shak S, et al.: Use of chemotherapy plus a monoclonal antibody against HER2 for metastatic breast cancer that overexpresses HER2. N Engl J Med 2001;344:783-792.

13 Marty M, Cognetti F, Maraninchi D, et al.: Randomized phase II trial of the efficacy and safety of trastuzumab combined with docetaxel in patients with human epidermal growth factor receptor 2-positive metastatic breast cancer administered as first-line treatment: the M77001 study group. J Clin Oncol 2005;23:4265-4274.

14 Kaufman B, Mackey JR, Clemens MR, Bapsy PP, Vaid A, Wardley A, Tjulandin S, Jahn M, Lehle M, Feyereislova A, Révil C, Jones A: Trastuzumab plus anastrozole versus anastrozole alone for the treatment of postmenopausal women with human epidermal growth factor receptor 2-positive, hormone receptor-positive metastatic breast cancer: results from the randomized phase III TAnDEM study. J Clin Oncol 2009;27:5529-5537. 